\title{
Comparison between Anterior Cervical Decompression with Fusion and Posterior Cervical Fusion with Wide Fac- etectomy for Treatment of Severe Bony Foraminal Steno- sis
}

\author{
Subum Lee, ${ }^{1,2}$ Dae-Chul Cho, ${ }^{1,2}$ Haemin Chon, ${ }^{3, *}$ Sung Woo Roh, ${ }^{3}$ Il Choi, ${ }^{4}$ Jin Hoon Park ${ }^{3}$ \\ Department of Neurosurgery, Kyungpook National University Hospital, Daegu, Korea \\ Department of Neurosurgery, ${ }^{2}$ School of Medicine, Kyungpook National University, Daegu, Korea \\ Department of Neurosurgery, ${ }^{3}$ Asan Medical Center, University of Ulsan College of Medicine, Seoul, Korea \\ Department of Neurosurgery, ${ }^{4}$ Dongtan Sacred Heart Hospital, University of Hallym University, Hwaseong, Korea
}

Objective : To compare the anterior cervical discectomy and fusion (ACDF) and posterior cervical fusion (PCF) with wide facetectomy in the treatment of parallel-shaped bony foraminal stenosis (FS).

Methods : Thirty-six patients underwent surgery due to one-or-two levels of parallel-shaped cervical FS. ACDF was performed in 16 patients, and PCF using CPS was performed in 20 patients. All patients were followed up at 1, 3, 6, and 12 months postoperatively. Standardized outcome measures such as Numeric rating scale (NRS) score for arm/neck pain and Neck disability index (NDI) were evaluated. Cervical radiographs were used to compare the C2-7 Cobb's angle, segmental angle, and fusion rates.

Results : There was an improvement in NRS scores after both approaches for radicular arm pain (mean change -6.78 vs. -8.14 , $p=0.012$ ), neck pain (mean change -1.67 vs. $-4.36, p=0.038$ ), and NDI score (-19.69 vs. $-18.15, p=0.794)$. The segmental angle improvement was greater in the ACDF group than in the posterior group $\left(9.4^{\circ} \pm 2.7^{\circ}\right.$ vs. $\left.3.3^{\circ} \pm 5.1^{\circ}, p=0.004\right)$. However, there was no significant difference in C2-7 Cobb angle between groups $\left(16.2^{\circ} \pm 7.9^{\circ}\right.$ vs. $\left.14.8^{\circ} \pm 8.5^{\circ}, p=0.142\right)$. As a complication, dysphagia was observed in one case of the ACDF group.

Conclusion : In the treatment of parallel-shaped bony FS up to two surgical levels, segmental angle improvement was more favorable in patients who underwent ACDF. However, PCF with wide facetectomy using CPS should be considered as an alternative treatment option in cases where the anterior approach is burdensome.

Key Words : Cervical radiculopathy · Cervical spine · Facet joint · Foraminotomy · Spinal fusion.

- Received : September 4, 2020 •Revised : October 21, 2020 •Accepted : October 28, 2020

- Address for reprints : II Choi

Department of Neurological Surgery, Dongtan Sacred Heart Hospital, University of Hallym University, 7 Keunjaebong-gil, Hwaseong 18450, Korea

Tel : +82-31-8086-2410, Fax : +82-31-8086-2584, E-mail : heycai@naver.com, ORCID : https://orcid.org/0000-0003-0120-6564

\author{
Jin Hoon Park \\ Department of Neurological Surgery, Asan Medical Center, University of Ulsan College of Medicine, 88 Olympic-ro 43-gil, Songpa-gu, Seoul 05505, Korea \\ Tel : +82-2-3010-3550, Fax : +82-2-476-6738, E-mail : jhpark@amc.seoul.kr, ORCID : https://orcid.org/0000-0002-0903-3146 \\ ${ }^{*}$ Current affiliation : Graduate School of Medical Science and Engineering, Korea Advanced Institute of Science and Technology (KAIST), Daejeon, Korea
}

This is an Open Access article distributed under the terms of the Creative Commons Attribution Non-Commercial License (http://creativecommons.org/licenses/by-nc/4.0) which permits unrestricted non-commercial use, distribution, and reproduction in any medium, provided the original work is properly cited. 


\section{INTRODUCTION}

Although a cervical posterior foraminotomy without fusion is a good surgical option for treatment of mild or moderate cervical foraminal stenosis (FS), it is not appropriate for the treatment of severe bony FS when the nerve root is compressed across the entire path of the cervical foramen ${ }^{8,10,11,15,16,30,32)}$. To date, few studies have compared anterior cervical discectomy and fusion (ACDF) and posterior cervical fusion (PCF) in the treatment of cervical FS. Previous studies including ours have found that ACDF or posterior facetectomy with fusion are appropriate when compression of the entire foraminal path by bony spurs and seen as parallel-shaped FS in axial computed tomography (CT) images ${ }^{7,10)}$.

Since wide facetectomy for parallel-shaped FS is not possible with the lateral mass screw, we did PCF with cervical pedicle screw (CPS). Though there has been some controversy over the use of CPS in degenerative disease, CPS was used for sufficient facetectomy and foraminal decompression.

We previously demonstrated the effectiveness and safety of CPS placement even in patients with degenerative cervical spinal pathology such as parallel-shaped cervical $\mathrm{FS}^{5,9,17,20,21,25-27)}$. Here we compared ACDF with uncinate removal and PCF with wide facetectomy in the treatment of parallel-shaped severe bony cervical FS. Additionally, we introduce an advantage of using CPS during PCF.

\section{MATERIALS AND METHODS}

\section{Patient population and inclusion criteria}

The study protocol was approved by the Institutional Review Board of Asan Medical Center (Approval No. AMC IRB 2020-0700). We retrospectively reviewed medical records of patients who underwent cervical spinal surgery by ACDF or PCF to treat one-or-two levels of parallel-shaped FS between March 2012 and August 2016. The selection of surgical approach depended on the surgeons' preferences. No patients with cervical myelopathy or cervical soft disc herniation were included in this study. Only patients with radiculopathy caused by bony hypertrophy through the cervical foramen who did not respond to non-operative treatment for more than two months were included. Especially, the shape of narrowed foramen on axial CT scan was seen only as a parallelshape, not $\mathrm{V}$-shape, was included, and this was regarded as the narrowing through an entire path of the foramen (Fig. 1) ${ }^{10}$. This type of parallel-shaped bony FS with neuroforaminal compression is the definition of severe bony FS in this study.

We included patients who were follow-up for at least 12 months. We excluded patients with serious cardiovascular, pulmonary, or cerebrovascular comorbidity, or history of anticoagulant treatment (i.e., warfarin or clopidogrel). All patients were underwent preoperative CT scans, magnetic resonance imaging, and X-ray imaging.
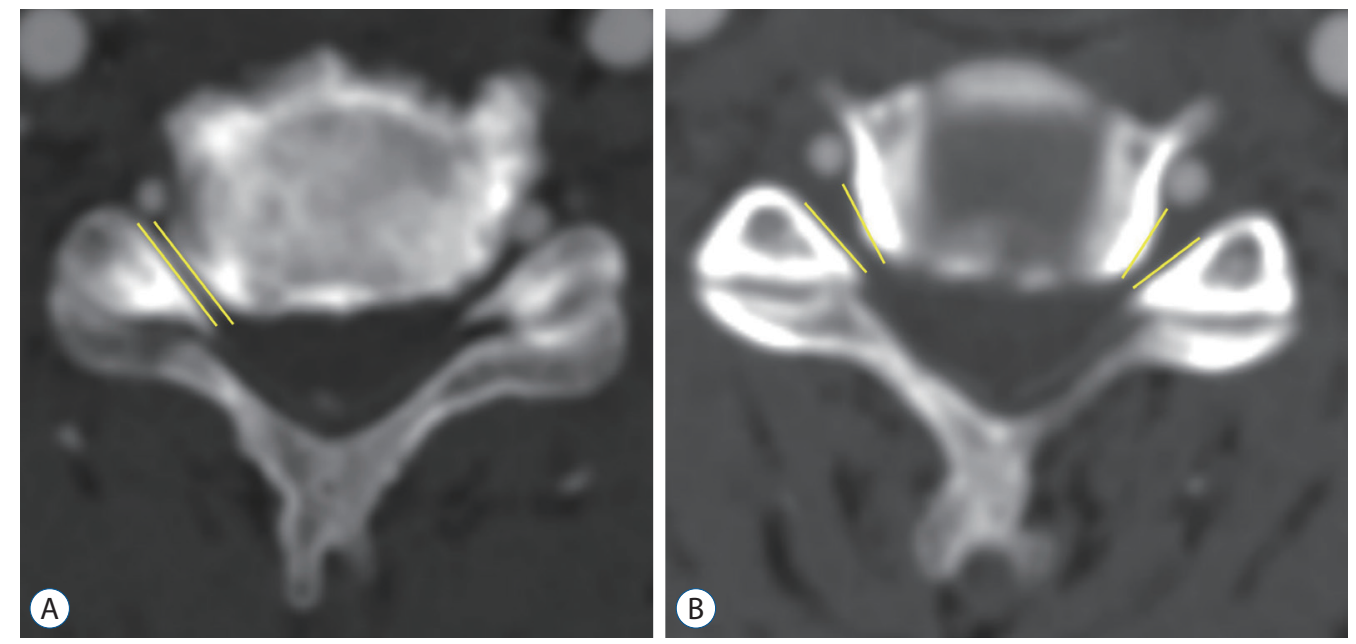

Fig. 1. The shape of narrowed foramen on axial computed tomography scans. A : Parallel-shaped foraminal stenosis (FS) on the intervertebral level. The entire path of foramen was narrowed from the entrance zone to the exit zone. B : In contrast to parallel-shaped FS, V-shaped FS becomes wider at the exit zone. 


\section{Surgical methods of ACDF and PCF}

For an ACDF, the standard Smith-Robinson approach was used. After level identification with X-ray examination, discectomy was performed. To achieve a wide foraminal decompression, the uncinate process removal of the affected site was performed. Properly sized interbody spacers made of iliac bone or allograft block were inserted, followed by anterior plate fixation $^{4}$.

For PCF procedures, freehand CPS insertion was primarily considered if the outer diameter of the cervical pedicle was greater than $3.0 \mathrm{~mm}$ on axial CT images. Patients were placed prone and Gardner-Wells tongs were applied with 3 or 5 pounds of traction to achieve a maximally horizontal head position. Motor evoked potential monitoring was used throughout the procedure. The entry point of the screw was determined by the notch level in the sagittal plane, medial to the lateral border of the superior articular process by onequarter of its width in the axial plane. A small pilot hole was made at the predetermined entry point with a 1.8 -mm diameter match head-type burr. After forming a trajectory through the cancellous channel of the pedicle and tapping with a 3.5$\mathrm{mm}$ diameter tap, the screw was inserted. If we were not sure of the safety of the pedicle trajectory after repeated probing with a ball tip probe, we converted to lateral mass screw placement. A more detailed technical description of our technique was described previously $^{13,17,21,25)}$.

After CPS placement, a wide facetectomy was performed for decompression of the entire path of the nerve root. After cutting of inferior articular process with an osteotome, drilling of the superior articular process was done with a $3.0 \mathrm{~mm}$ sized match head type burr and 1 or $2 \mathrm{~mm}$ Kerrison rongeur. We considered complete decompressin to be achieved after complete removal of the tip of the superior articular process and identification of the lateral dura margin and origin of the nerve root (Fig. 2). Further ligament flavectomy was not performed, and redundancy of soft tissue was identified only by palpation with a Penfield number 4 dissector. Cancellous bone was exposed by drilling with a $3.0 \mathrm{~mm}$ match head type burr on the posterior surface of the lateral mass and inside the facet joint. Allograft bone chips (TBI Inc., San Rafael, CA, USA) were used for posterolateral fusion (i.e., an onlay bone graft on the decorticated lateral mass and inside the facet joint $)^{19)}$. A postoperative CT scan was performed immediately to check the screw placement and to evaluate the amount of foraminal decompression in all patients.

\section{Comparison of clinical and radiological out- comes between two groups}

All patients were advised to wear a soft collar for four weeks after the operation and were followed up at 1, 3, 6, and 12 months. We compared clinical outcomes between the two groups, including any change in the Numeric rating scale (NRS) score for radiating arm pain and neck pain, complications, surgical time, estimated blood loss (EBL), pre and post
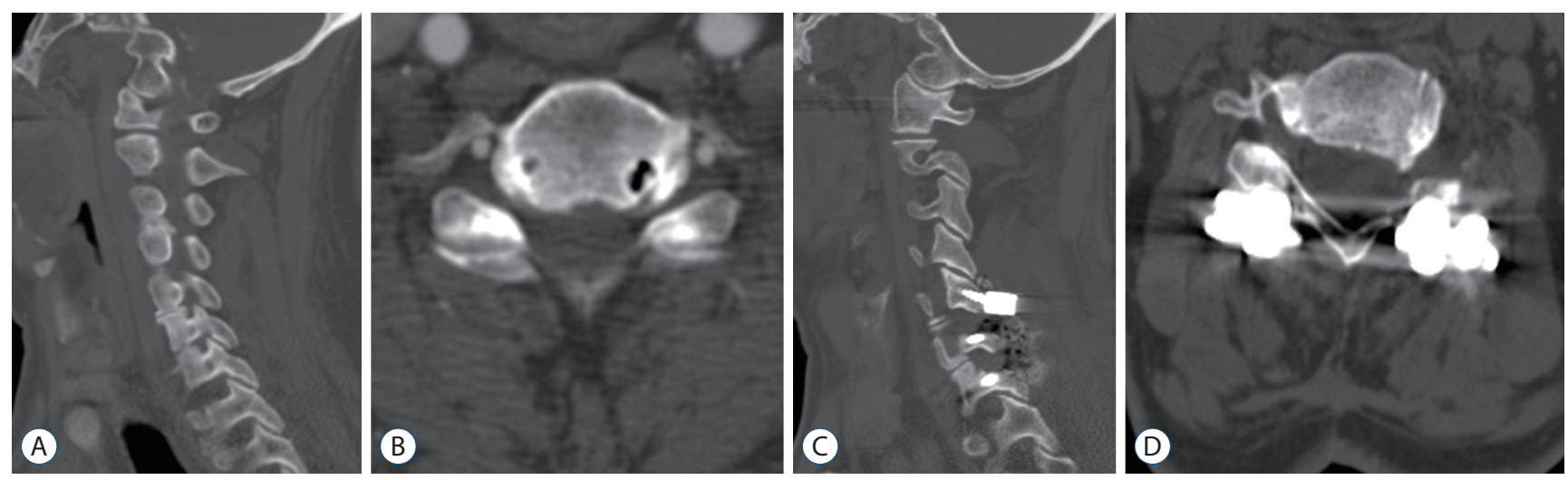

Fig. 2. A 70-year-old man with tingling in both arms and left elbow flexion weakness. Severe parallel shape foraminal stenosis (FS) was seen on preoperative computed tomography (CT) imaging, with the left FS being more pronounced. A : Preoperative sagittal CT image show the C5-6, $\mathrm{C} 6-7$ foramen. B : Preoperative axial CT image of the C5-6 level foramen. C : Sagittal CT image of 12 months after C5-6 and C6-7 wide facetectomy (Ponte osteotomy) with fusion. Cervical pedical screws were inserted into both sides of $\mathrm{C} 6$ and $\mathrm{C} 7$, and lateral mass screws were inserted into both sides of the C5. D : Axial CT image of the C5-6 level 12 months after surgery. Both sides of the C6 superior articular processes were removed, and the entire path of C5-6 foramen was widened. 
operative white blood cell (WBC) count, and in the Neck disability index (NDI) at the 12 months follow-up were used in this study.

We reviewed a series of lateral cervical X-rays of patients in an upright, neutral position and measured the Cobb angle between the lower border of the C2 body and the lower border of the C7 body to evaluate cervical sagittal alignment (Fig. 3). Radiological fusion was confirmed when there was stability on a flexion-extension lateral dynamic X-ray view on the last follow up (i.e., the motion between the adjacent spinous processes between the fusion segment was $<2 \mathrm{~mm}$ ). Additionally, imaging of patients who underwent CT scans about 1 year after the surgery were reviewed to evaluate bone bridge formation.

\section{Statistical analysis}

We used SPSS ver. 18.0 statistical software package (SPSS Inc., Chicago, IL, USA) for statistical analysis. This study presented comparing data from 16 and 20 subjects $(10 \leq \mathrm{n} \leq 30)$. The normality of the distributions was assessed using the Shapiro-Wilk test. Groups were compared for demographic data (mean age, follow-up duration), clinical outcomes (surgical time, WBC count), and radiologic outcomes of surgery by student t-test after the normality test (Tables 1-3). The NRS of arm and neck pain, EBL for clinical outcomes were compared by Mann-Whitney U test (Table 2). Group differences were analyzed using the chi-square tests (Pearson and Fisher exact tests, as appropriate) for categorical variables. A linear mixed model for the change scores (changes from baseline) was also used to test the time-by-group interaction (Table 4). $p$-values $<0.05$ were considered to indicate statistical significance.

\section{RESULTS}

Sixteen patients underwent ACDF, and 20 patients underwent PCF using CPS. There were no significant differences between the two groups in terms of sex, age, follow-up duration, operation level, and surgical level. In both groups, surgery for the C5-7 level was the most common (Ant, 43.8\%; Post, 55\%), and two-level surgery was more common than one-level surgery (75\% vs. 25\%). Patient characteristics are described in Table 1.

Preoperative baseline and postoperative outcomes are pre-
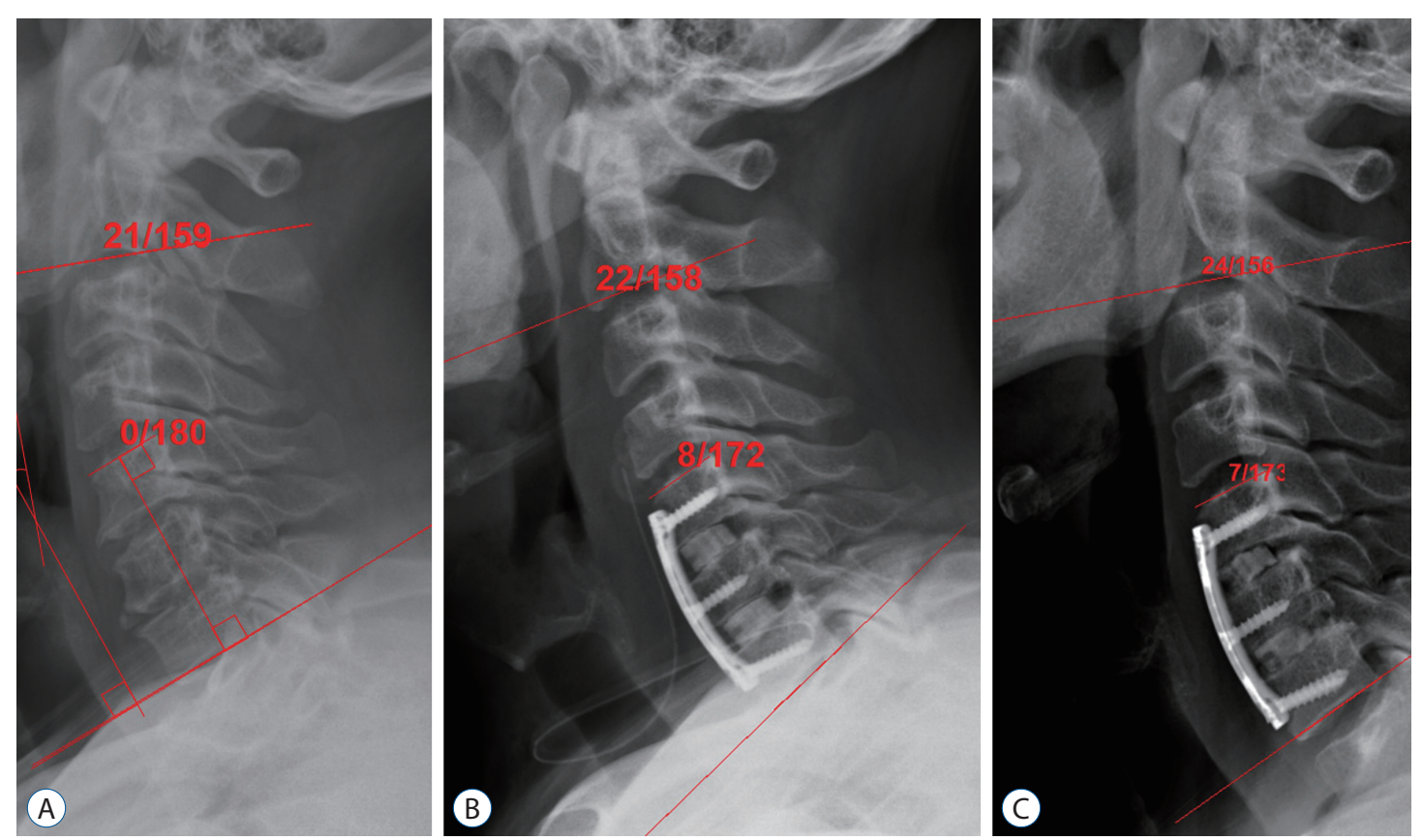

Fig. 3. A lateral cervical X-ray of a patient in a neutral position shows the C2-7 Cobb angle measurement between the lower border of the $\mathrm{C} 2$ body and the lower border of the $\mathrm{C} 7$ body. The segmental angle measurement is made between the lower border of the distal instrumented vertebral body and the upper border of the proximal instrumented vertebral body. A : Preoperative image. B : Immediate postoperative image. The segmental angle of surgical index level increased after anterior cervical decompression, C5-6-7. C : X-ray image of 12 months after surgery. The segmental angle and C2-7 Cobb angle remained well after 12 months. 
Table 1. Characteristics of patients who underwent ACDF with unicinate removal or PCF with wide facetectomy for parallel-shaped bony FS

\begin{tabular}{|c|c|c|c|}
\hline & $\operatorname{ACDF}(n=16)$ & $P C F(n=20)$ & $p$-value \\
\hline Sex, male : female & $11: 5$ & $19: 1$ & 0.069 \\
\hline Age (years) & $52.8 \pm 11.2$ & $58.7 \pm 9.5$ & 0.096 \\
\hline Follow up duration (months) & $22.4 \pm 11.6$ & $20.8 \pm 9.8$ & 0.649 \\
\hline Operative level & & & 0.459 \\
\hline C3-5 & $2(12.5)$ & $1(5.0)$ & \\
\hline C4-6 & $3(18.8)$ & $3(15.0)$ & \\
\hline C5-6 & $3(18.8)$ & $1(5.0)$ & \\
\hline C5-7 & $7(43.8)$ & $11(55.0)$ & \\
\hline C6-7 & $1(6.3)$ & $4(20.0)$ & \\
\hline Number of surgical level & & & 0.652 \\
\hline 1 level & $4(25.0)$ & $5(25.0)$ & \\
\hline 2 level & $12(75.0)$ & $15(75.0)$ & \\
\hline \multirow[t]{3}{*}{ Comorbidity } & $2(12.5)$ & $1(5.3)$ & 0.582 \\
\hline & Lou Gehrig's disease 1 & Stroke 1 & \\
\hline & T-spine metastatis 1 & & \\
\hline
\end{tabular}

Values are presented as mean \pm standard deviation or number (\%). ACDF : anterior cervical discectomy and fusion, PCF : posterior cervical fusion, FS : foraminal stenosis

sented in Tables 2 and 3. There were no significant differences between the two groups for preoperative or postoperative radiating arm pain. In both groups, arm pain improved at 1 month postoperatively and improvements were maintained through the final follow-up period. Preoperative neck pain was significantly higher in the PCF group (NRS : ACDF group, 1.7 vs. PCF group, 4.4). There were significant differences in postoperative NRS scores for neck pain from 1 month to 6 months, and there was no significant difference between the two groups at 12 months after surgery. For this reason, in the linear mixed model analysis, the neck pain change of the PCF group was significantly greater over time (Table 4). NDI scores improved in both groups, and there was no difference between the two groups. There was no significant difference in complication proportion of complications between groups, and there was 1 case of dysphagia in anterior group. EBL was significantly higher in the PCF group (EBL : ACDF group, $91.25 \pm 62.91 \mathrm{~mL}$ vs. PCF group, $420.00 \pm 123.97 \mathrm{~mL}$ ). Other indirect factors for measuring invasiveness (surgical time, postoperative change of WBC count) have no significant differences between the two groups.

Radiologic outcomes are presented in Tables 3 and 4. All patients in this study had stability on the last dynamic X-ray (interspinous distance : ACDF group, $0.9 \pm 0.6 \mathrm{~mm}$; PCF group, $0.4 \pm 0.2 \mathrm{~mm}$ ). Postoperative 12 months CT scans were taken of 26 patients (ACDF, 13; PCF, 13). All the CT scans of 26 patients showed the formation of a contiguous bony bridge. By definition, we evaluated that bone fusion was achieved in all patients. Both the Cobb and segmental angles of the $\mathrm{C} 2-7$ vertebrae of the ACDF group were larger than those in the PCF group. However, there were no significant differences in the analysis by linear mixed model. At the last follow-up, the segmental angle was significantly larger in the ACDF group than in the PCF group $\left(9.4^{\circ}\right.$ vs. $\left.3.3^{\circ}, p<0.004\right)$.

\section{DISCUSSION}

We compared the outcomes of ACDF with PCF using CPS in a very selective and homogenous group of patients with parallel-shaped FS. Although decompressive surgery such as a posterior cervical foraminotomy is approprate for common cervical FS, it is not appropriate for treatment of an FS with advanced stage degeneration where the entire path of the foramen is narrowed from the entrance zone of the nerve root of the spinal canal to the exit zone. In this situation, ACDF with 
Table 2. Clinical outcomes in patients

\begin{tabular}{|c|c|c|c|}
\hline & $\operatorname{ACDF}(n=16)$ & PCF $(n=20)$ & $p$-value \\
\hline \multicolumn{4}{|l|}{ Mean NRS of arm pain } \\
\hline Pre-operation & $8.2 \pm 0.8$ & $8.6 \pm 1.0$ & 0.208 \\
\hline Postoperative $1 \mathrm{M}$ & $1.2 \pm 0.7$ & $1.2 \pm 1.9$ & 0.967 \\
\hline Postoperative $3 \mathrm{M}$ & $0.9 \pm 0.9$ & $0.8 \pm 1.3$ & 0.905 \\
\hline Postoperative $6 \mathrm{M}$ & $1.0 \pm 1.4$ & $0.5 \pm 1.0$ & 0.341 \\
\hline Postoperative $12 \mathrm{M}$ & $0.6 \pm 1.2$ & $0.4 \pm 0.8$ & 0.651 \\
\hline Last follow-up & $1.4 \pm 1.2$ & $0.5 \pm 1.1$ & 0.100 \\
\hline \multicolumn{4}{|l|}{ Mean NRS of neck pain } \\
\hline Pre-operation & $1.7 \pm 2.3$ & $4.4 \pm 3.3$ & 0.010 \\
\hline Postoperative $1 \mathrm{M}$ & $0.8 \pm 0.9$ & $3.2 \pm 2.7$ & 0.004 \\
\hline Postoperative $3 \mathrm{M}$ & $0.5 \pm 1.1$ & $1.7 \pm 1.7$ & 0.026 \\
\hline Postoperative $6 \mathrm{M}$ & $0.2 \pm 0.4$ & $1.2 \pm 1.3$ & 0.028 \\
\hline Postoperative $12 \mathrm{M}$ & $0.5 \pm 1.2$ & $0.4 \pm 0.8$ & 0.910 \\
\hline Last follow-up & $0.0 \pm 0.0$ & $0.5 \pm 1.5$ & 0.179 \\
\hline \multicolumn{4}{|l|}{ Complications } \\
\hline \multirow[t]{3}{*}{ Any complication, yes } & $2(12.5)$ & $1(5.0)$ & 0.660 \\
\hline & Dysphagia 1 & C5 palsy 1 & \\
\hline & Myelitis 1 & & \\
\hline Dysphagia, yes & $1(6.3)$ & $0(0.0)$ & 0.457 \\
\hline \multicolumn{4}{|l|}{ Invasiveness } \\
\hline Surgical time (minutes) & $162.44 \pm 42.34$ & $186.75 \pm 41.33$ & 0.092 \\
\hline $\mathrm{EBL}(\mathrm{mL})$ & $91.25 \pm 62.91$ & $420.00 \pm 123.97$ & $<0.001$ \\
\hline WBC pre-operation $(/ \mu \mathrm{L})$ & $6962.5 \pm 1831.9$ & $7035.0 \pm 1956.7$ & 0.910 \\
\hline Postoperative 1 day & $9693.8 \pm 2841.0$ & $9325.0 \pm 2693.6$ & 0.693 \\
\hline Post-pre change & $2731.3 \pm 2200.5$ & $2290.0 \pm 1957.4$ & \\
\hline Post-pre paired t-test & $p<0.001$ & $p<0.001$ & \\
\hline
\end{tabular}

Values are presented as mean \pm standard deviation or number (\%). ACDF : anterior cervical discectomy and fusion, PCF : posterior cervical fusion, NRS : Numeric rating scale, $\mathrm{M}$ : months, EBL : estimated blood loss, WBC : white blood cell

uncinate process removal or PCF with wide foraminal decompression through facet resection is recommended to achieve sufficient decompression ${ }^{7,10,11,24)}$.

We previously reported that parallel shaped bony FS is an indication of ACDF or posterior fusion surgery with aggressive foraminotomy ${ }^{10)}$. In this study, two surgeons (S.W.R. and J.H.P.) performed the surgery according to their preference for the parallel shape FS. PCF was performed in patients with relatively severe facet hypertrophy and degenerative spondylosis. The results showed that the PSF group's preoperative neck pain was greater than that of the ACDF group (neck pain NRS :

PCF, $4.4 \pm 3.3$; ACDF, $1.7 \pm 2.3 ; p=0.010$ )
ACDF remains the gold standard for treating cervical spondylotic radiculopathy and FS due to discs and spurs at one or two levels ${ }^{23)}$. However, additional uncinated process removal during ACDF has been associated with higher incidence of subsidence despite similar fusion rate ${ }^{17-19,22)}$. In the case of parallel shaped FS with prominent facet joint hypertrophy, iatrogenic dorsal root compression by superior articular process projecting could occur after ACDF. In addition, the anterior approach can cause complications such as dysphagia and hoarseness. Considering this, the posterior approach may be appropriate for patients with a history of previous anterior neck surgery or radiation therapy and severe spondylosis with 
Table 3. Radiologic outcomes

\begin{tabular}{|c|c|c|c|}
\hline & $\operatorname{ACDF}(n=16)$ & PCF $(n=20)$ & $p$-value \\
\hline Interspinous distance, on the last dynamic X-ray (mm) & $0.9 \pm 0.6$ & $0.4 \pm 0.2$ & 0.006 \\
\hline Fusion bridge formation, in case of postoperative 12 M CT acquired & 13/13 (100.0) & $13 / 13(100.0)$ & 0.693 \\
\hline \multicolumn{4}{|l|}{ C2-7 Cobb angle $\left(^{\circ}\right)$} \\
\hline Pre-operation & $14.1 \pm 11.9$ & $12.7 \pm 9.9$ & 0.687 \\
\hline Postoperative $1 \mathrm{M}$ & $15.8 \pm 10.2$ & $12.9 \pm 7.8$ & 0.430 \\
\hline Postoperative $3 \mathrm{M}$ & $15.9 \pm 9.6$ & $15.8 \pm 10.1$ & 0.959 \\
\hline Postoperative $6 \mathrm{M}$ & $13.5 \pm 8.6$ & $12.4 \pm 8.8$ & 0.778 \\
\hline Postoperative $12 \mathrm{M}$ & $15.1 \pm 8.4$ & $14.0 \pm 7.3$ & 0.758 \\
\hline Last follow-up & $16.2 \pm 7.9$ & $14.8 \pm 8.5$ & 0.691 \\
\hline \multicolumn{4}{|l|}{ Segmental angle $\left({ }^{\circ}\right)$} \\
\hline Pre-operation & $3.1 \pm 5.6$ & $2.9 \pm 6.0$ & 0.955 \\
\hline Postoperative $1 \mathrm{M}$ & $8.1 \pm 6.9$ & $4.4 \pm 4.6$ & 0.126 \\
\hline Postoperative $3 \mathrm{M}$ & $8.4 \pm 7.2$ & $5.9 \pm 5.8$ & 0.303 \\
\hline Postoperative $6 \mathrm{M}$ & $7.9 \pm 7.3$ & $5.2 \pm 4.6$ & 0.289 \\
\hline Postoperative $12 \mathrm{M}$ & $7.9 \pm 4.9$ & $6.4 \pm 6.1$ & 0.536 \\
\hline Last follow-up & $9.4 \pm 2.7$ & $3.3 \pm 5.1$ & 0.004 \\
\hline
\end{tabular}

Values are presented as mean \pm standard deviation or number (\%). ACDF : anterior cervical discectomy and fusion, PCF : posterior cervical fusion, M : months, CT : computed tomography

Table 4. Linear mixed model showing the difference between groups according to the change of time

\begin{tabular}{|c|c|c|c|c|c|c|c|}
\hline Change* $^{*}$ & F/U months & $\begin{array}{l}\text { ACDF } \\
(n=16)\end{array}$ & $\begin{array}{c}\text { Time } \\
p \text {-value }\end{array}$ & $\begin{array}{c}\text { PCF } \\
(n=20)\end{array}$ & $\begin{array}{c}\text { Time } \\
p \text {-value }\end{array}$ & $\begin{array}{c}\text { Timexgroup } \\
p \text {-value }\end{array}$ & $\begin{array}{c}\text { Group } \\
p \text {-value }\end{array}$ \\
\hline \multirow[t]{5}{*}{ C2-7 Cobb angle $\left(^{\circ}\right)$} & 1 & $16(1.63 \pm 10.92)$ & 0.916 & $12(-0.42 \pm 6.60)$ & 0.120 & 0.302 & 0.672 \\
\hline & 3 & $15(1.33 \pm 11.15)$ & & $16(2.00 \pm 6.29)$ & & & 0.949 \\
\hline & 6 & $11(0.91 \pm 11.96)$ & & $12(2.92 \pm 5.07)$ & & & 0.513 \\
\hline & 12 & $13(0.23 \pm 8.75)$ & & $9(1.56 \pm 7.43)$ & & & 0.581 \\
\hline & Last & $9(1.67 \pm 9.43)$ & & $14(5.57 \pm 4.54)$ & & & 0.142 \\
\hline \multirow[t]{5}{*}{ Segment angle $\left(^{\circ}\right)$} & 1 & $16(5.00 \pm 8.05)$ & 0.974 & $12(1.50 \pm 5.95)$ & 0.793 & 0.848 & 0.226 \\
\hline & 3 & $15(5.33 \pm 8.71)$ & & $16(2.19 \pm 5.39)$ & & & 0.188 \\
\hline & 6 & $11(6.09 \pm 9.27)$ & & $12(2.83 \pm 5.70)$ & & & 0.300 \\
\hline & 12 & $13(4.62 \pm 6.46)$ & & $9(1.78 \pm 6.30)$ & & & 0.218 \\
\hline & Last & $9(6.33 \pm 6.02)$ & & $14(1.43 \pm 4.93)$ & & & 0.292 \\
\hline \multirow[t]{5}{*}{ Arm pain Score, NRS } & 1 & $16(-7.00 \pm 0.97)$ & 0.340 & $18(-7.56 \pm 2.36)$ & 0.615 & 0.467 & 0.296 \\
\hline & 3 & $15(-7.27 \pm 1.10)$ & & $17(-7.76 \pm 1.68)$ & & & 0.431 \\
\hline & 6 & $11(-7.00 \pm 1.26)$ & & $14(-8.43 \pm 1.70)$ & & & 0.088 \\
\hline & 12 & $12(-7.42 \pm 1.31)$ & & $9(-8.56 \pm 1.24)$ & & & 0.154 \\
\hline & Last & $9(-6.78 \pm 1.39)$ & & $14(-8.14 \pm 1.51)$ & & & 0.012 \\
\hline \multirow[t]{5}{*}{ Neck pain score, NRS } & 1 & $16(-0.88 \pm 1.50)$ & 0.751 & $17(-0.82 \pm 4.33)$ & 0.006 & 0.021 & 0.800 \\
\hline & 3 & $15(-1.33 \pm 1.76)$ & & $17(-2.59 \pm 3.66)$ & & & 0.185 \\
\hline & 6 & $11(-1.00 \pm 1.34)$ & & $14(-2.64 \pm 3.50)$ & & & 0.103 \\
\hline & 12 & $12(-1.25 \pm 2.42)$ & & $9(-4.33 \pm 4.30)$ & & & 0.026 \\
\hline & Last & $9(-1.67 \pm 2.35)$ & & $14(-4.36 \pm 3.71)$ & & & 0.038 \\
\hline NDI score & Last & $16(-19.69 \pm 13.68)$ & & $20(-18.15 \pm 20.05)$ & & & 0.794 \\
\hline
\end{tabular}

Values are presented as number (mean \pm standard deviation). ${ }^{*}$ Corresponding time value - preoperative value, mean (least squares means) : mean estimated by linear mixed model, $p$-value of NDI score change was derived with t-test. F/U : follow up, ACDF : anterior cervical discectomy and fusion, PCF : posterior cervical fusion, NRS : Numeric rating scale, NDI : Neck disability index 
malalignment.

When using PCF for parallel shaped FS, it is necessary to remove the entire facet joint to achieve sufficient decompression to the lateral side of the foramen, which inevitably requires pedicle fixation. This wide decompression is similar to Ames' grade 2 osteotomy (complete facet joint/Ponte osteotomy) for deformity correction ${ }^{3)}$. However, the lateral masses may not be robust enough to apply significant compressive forces, and pedicle fixation with CPS should be considered in these situations ${ }^{31}$. This is because the tip or thread of the lateral mass screw may be exposed during the resection of a superior and inferior articular process (Fig. 4). Furthermore, the lateral mass screw could be limited when combined with wide facetectomy because of the less bone and screw engagement and lower stability after cyclic loading.

In addition, the fusion bed around the lateral mass, which is an important bone graft recipient site, may be smaller because of the area occupied by the head of lateral mass screw ${ }^{19,29)}$. To connect the remaining superior-inferior auricular process after decompression through a bony fusion, we believe that having sufficient healthy surface to receive bone graft and biomechanical stability during bone fusion process are the most important factors. We previously showed complete fusion rate only with an on-lay allograft bone and CPS used in this $\mathrm{FS}^{19}$.

The biomechanical advantage of the CPS over the lateral mass screw has been previously established. Despite these bio-

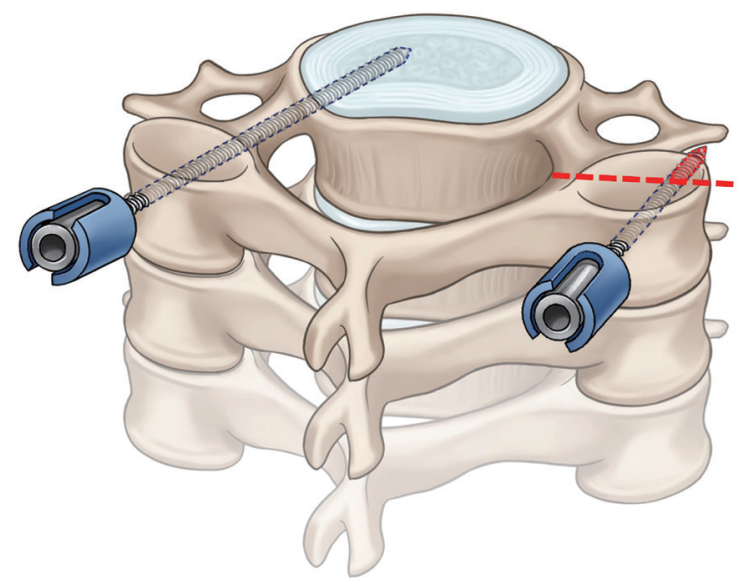

Fig. 4. An illustration showing an exposed screw tip or thread of a lateral mass screw during resection of the superior and inferior articular process. In cases of wide facetectomy (red dashed line), the lateral mass screw is partially exposed, but the trajectory of the cervical pedicle screw is not affected by it. mechanical benefits, the risk of possible neurovascular complications have been identified as areas of concern $^{2,14}$. Furthermore, there has been some controversy over the use of CPS in degenerative cervical disease. However, we have reported several times on the safety of CPS fixation in various patient groups with cervical spinal disease including $\mathrm{FS}^{5,13,17,19-21,25,26)}$. Our findings have led us to use the CPS instead of the lateral mass screw even in cases of degenerative spinal disease without much concern for neurovascular complications ${ }^{1,12,21)}$.

The outcomes of radiating arm pain were comparable between groups, and there was no difference in overall NDI scores and NRS neck pain scores at last follow-up. Although there were no differences in clinical outcomes overall between the two treatment methods, neck pain was significantly higher in patients who underwent PCF until 6 months after surgery. EBL of the PCF group was also significantly higher than the ACDF group, and it is an indirect indicator that PCF is more invasive than ACDF. This finding highlights a major disadvantage of conventional midline posterior surgical approaches for cervical fusion surgery as extensive subperiosteal dissection and detachment of paraspinal muscles from the lamina can lead to postoperative cervical muscular pain and spasming $^{30)}$. However, it should also be noted that the preoperative neck pain NRS scores were also significantly higher in the PCF group. We believe that the neck pain difference in the baseline is due to the fact that many patients with more severe degenerative spondylosis were selected to undergo PCF. The composition of the patient groups may have contributed to the more severe neck pain observed from baseline up to 6 months in the PCF group.

The C2-7 Cobb's angle for the evaluation of cervical alignment showed no difference in global cervical lordosis between the two groups. However, the ACDF group had a larger mean segmental angle immediately after surgery, and this difference between was maintained statistically significant at the last follow-up. This gap indicates that ACDF, which can support the anterior column by cage insertion, is more favorable for segmental angle correction and maintenance than PCF. As has previously been demonstrated in biomechanical studies, the presence of interbody cages significantly improves overall construct stiffness when compared with posterior-only implant systems ${ }^{6,28)}$.

Our study had several limitations. First, it was a retrospective observational study involving a small number of patients. 
Second, the severity of baseline neck pain scores differed between patients who received ACDF or PCF, suggesting a difference in the degree of spondylosis. Typically, the surgical indications of ACDF and PCF are not the same. In order to compare the two surgical methods objectively, our study needs a clear distinction for surgical indications. Third, postoperative 12-month CT scans were not performed on all patients included in this study to assess bone fusion. Last, although complemented by a linear mixed model, there was a loss of the interval values of some patients during the whole follow-up period repeated measurements.

\section{CONCLUSION}

ACDF with uncinate process removal is better than PCF in treating parallel shaped bony FS up to two surgical levels in terms of maintaining larger segmental angles and less postoperative neck pain. However, in situations with severe cervical spondylosis with deformity or where an anterior approach is difficult, PCF with wide facetectomy using CPS may be one alternative treatment option for parallel shaped FS.

\section{CONFLICTS OF INTEREST}

No potential conflict of interest relevant to this article was reported.

\section{INFORMED CONSENT}

This type of study does not require informed consent.

\section{AUTHOR CONTRIBUTIONS}

\author{
Conceptualization : SWR, JHP \\ Data curation : SL, HC \\ Formal analysis : SL, IC \\ Funding acquisition : SWR, JHP \\ Methodology : SWR, IC \\ Project administration : DCC, JHP \\ Visualization : DCC, HC
}

\author{
Writing - original draft : SL, IC \\ Writing - review \& editing : SL, DCC, IC, JHP
}

\section{ORCID}

$\begin{array}{ll}\text { Subum Lee } & \text { https://orcid.org/0000-0003-4732-8137 } \\ \text { Dae-Chul Cho } & \text { https://orcid.org/0000-0002-2899-8015 } \\ \text { Haemin Chon } & \text { https://orcid.org/0000-0003-1998-4460 } \\ \text { Sung Woo Roh } & \text { https://orcid.org/0000-0001-6562-4154 } \\ \text { Il Choi } & \text { https://orcid.org/0000-0003-0120-6564 } \\ \text { Jin Hoon Park } & \text { https://orcid.org/0000-0002-0903-3146 }\end{array}$

\section{References}

1. Abumi K : Cervical spondylotic myelopathy: posterior decompression and pedicle screw fixation. Eur Spine J 24 Suppl 2 : 186-196, 2015

2. Abumi $K$, Ito $M$, Sudo $H$ : Reconstruction of the subaxial cervical spine using pedicle screw instrumentation. Spine (Phila Pa 1976) 37 : E349-E356, 2012

3. Ames CP, Smith IS, Scheer JK, Shaffrey Cl, Lafage V, Deviren V, et al. : A standardized nomenclature for cervical spine soft-tissue release and osteotomy for deformity correction: clinical article. J Neurosurg Spine 19 : 269-278, 2013

4. Bartolomei J, Sonntag V : Anterior approach including cervical corpectomy in Winn HR, Youmans JR (eds) : Youmans Neurological Surgery, ed 5. Philadelphia : Saunders, 2004, pp4431-4445

5. Chon H, Park JH : Cervical vertebral body fracture with ankylosing spondylitis treated with cervical pedicle screw: a fracture body overlapping reduction technique. J Clin Neurosci 41 : 150-153, 2017

6. Cunningham BW, Sefter JC, Shono Y, MCAfee PC : Static and cyclical biomechanical analysis of pedicle screw spinal constructs. Spine (Phila Pa 1976) 18 : 1677-1688, 1993

7. Dodwad SJ, Dodwad SN, Prasarn ML, Savage JW, Patel AA, Hsu WK : Posterior cervical foraminotomy: indications, technique, and outcomes. Clin Spine Surg 29 : 177-185, 2016

8. Fessler RG, Khoo LT : Minimally invasive cervical microendoscopic foraminotomy: an initial clinical experience. Neurosurgery 51(5 Suppl) : S37-S45, 2002

9. Gu BS, Choi SJ, Yoo B, Han KH, Park JK, Lee YS, et al. : An incidental finding of a radiopaque pill following cervical spinal surgery in a Parkinson's disease patient. Korean J Spine 12 : 153-155, 2015

10. Gu BS, Park JH, Seong HY, Jung SK, Roh SW : Feasibility of posterior cervical foraminotomy in cervical foraminal stenosis: prediction of surgical outcomes by the foraminal shape on preoperative computed tomography. Spine (Phila Pa 1976) 42 : E267-E271, 2017

11. Gutman $G$, Rosenzweig DH, Golan JD : Surgical treatment of cervical radiculopathy: meta-analysis of randomized controlled trials. Spine (Phila 
Pa 1976) 43 : E365-E372, 2018

12. Hasegawa K, Hirano T, Shimoda H, Homma T, Morita $\mathrm{O}$ : Indications for cervical pedicle screw instrumentation in nontraumatic lesions. Spine

(Phila Pa 1976) 33 : 2284-2289, 2008

13. Heo Y, Lee SB, Lee BJ, Jeong SK, Rhim SC, Roh SW, et al. : The learning curve of subaxial cervical pedicle screw placement: how can we avoid neurovascular complications in the initial period? Oper Neurosurg (Hagerstown) 17 : 603-607, 2019

14. Johnston TL, Karaikovic EE, Lautenschlager EP, Marcu D : Cervical pedicle screws vs. lateral mass screws: uniplanar fatigue analysis and residual pullout strengths. Spine J 6 : 667-672, 2006

15. Kang MS, Choi KC, Lee CD, Shin YH, Hur SM, Lee SH : Effective cervical decompression by the posterior cervical foraminotomy without discectomy. J Spinal Disord Tech 27 : 271-276, 2014

16. Kerry G, Hammer A, Ruedinger C, Ranaie G, Steiner HH : Microsurgical posterior cervical foraminotomy: a study of 181 cases. Br J Neurosurg 31 : 39-44, 2017

17. Kim HB, Lee MK, Lee YS, Sohn JY, Jung SK, Park JH : An assessment of the medial angle of inserted subaxial cervical pedicle screw during surgery: practical use of preoperative CT scanning and intraoperative Xrays. Neurol Med Chir (Tokyo) 57 : 159-165, 2017

18. Lee DH, Cho JH, Baik JM, Joo YS, Park S, Min WK, et al. : Does additional uncinate resection increase pseudarthrosis following anterior cervical discectomy and fusion? Spine (Phila Pa 1976) 43 : 97-104, 2018

19. Lee JK, Jung SK, Lee YS, Jeon SR, Roh SW, Rhim SC, et al. : Analysis of the fusion and graft resorption rates, as measured by computed tomography, 1 year after posterior cervical fusion using a cervical pedicle screw. World Neurosurg 99 : 171-178, 2017

20. Lee S, Jung SK, Kim HB, Roh SW, Jeon SR, Park JH : Postoperative non-pathological fever following posterior cervical fusion surgery : is laminoplasty a better preventive method than laminectomy? J Korean Neurosurg Soc 63 : 487-494, 2020

21. Lee S, Seo J, Lee MK, Jeon SR, Roh SW, Rhim SC, et al. : Widening of the safe trajectory range during subaxial cervical pedicle screw placement: advantages of a curved pedicle probe and laterally located starting point without creating a funnel-shaped hole. J Neurosurg Spine 27 : 150157, 2017

22. Lee SH, Lee JS, Sung SK, Son DW, Lee SW, Song GS : The effect of uncinate process resection on subsidence following anterior cervical discectomy and fusion. J Korean Neurosurg Soc 60 : 550-559, 2017

23. Nakagawa H, Saito K, Mitsugi T, Yagi K, Kanno A : Microdiscectomy and foraminotomy in cervical spondylotic myelopathy and radiculopathy: anterior versus posterior, microendoscopic surgery versus mini-open microsurgery. World Neurosurg 81 : 292-293, 2014

24. Pakzaban P : Ultrasonic total uncinectomy: a novel technique for complete anterior decompression of cervical nerve roots. Neurosurgery 10 Suppl 4 : 535-541; discussion 541, 2014

25. Park JH, Jeon SR, Roh SW, Kim JH, Rhim SC : The safety and accuracy of freehand pedicle screw placement in the subaxial cervical spine: a series of 45 consecutive patients. Spine (Phila Pa 1976) 39 : 280-285, 2014

26. Park JH, Roh SW, Rhim SC : A single-stage posterior approach with open reduction and pedicle screw fixation in subaxial cervical facet dislocations. J Neurosurg Spine 23 : 35-41, 2015

27. Park JH, Roh SW, Rhim SC : Response. J Neurosurg Spine $24: 673$, 2016

28. Polly DW Jr, Klemme WR, Cunningham BW, Burnette JB, Haggerty CJ, Oda I: The biomechanical significance of anterior column support in a simulated single-level spinal fusion. J Spinal Disord 13 : 58-62, 2000

29. Rho YJ, Choe WJ : Double crush syndrome caused by cervical spondylosis and vertebral artery loop. Eur Spine J 28 : 292-296, 2019

30. Roh SW, Kim DH, Cardoso AC, Fessler RG : Endoscopic foraminotomy using MED system in cadaveric specimens. Spine (Phila Pa 1976) 25 : 260-264, 2000

31. Tan LA, Riew KD, Traynelis VC : Cervical spine deformity-part 3: posterior techniques, clinical outcome, and complications. Neurosurgery 81 : 893-898, 2017

32. Zeidman SM, Ducker TB : Posterior cervical laminoforaminotomy for radiculopathy: review of 172 cases. Neurosurgery 33 : 356-362, 1993 